\title{
Effects of Acidic Environment on Dynamic Mechanical Properties and Porosity Evolution Characteristics of Coal
}

\author{
Shuang Gong $\mathbb{D},{ }^{1,2,3}$ Xiaojun Li $\mathbb{D}^{1},{ }^{1}$ Wen Wang, ${ }^{1,3}$ Shibin Yao, ${ }^{1}$ Juan Liu, ${ }^{1}$ and Dengyun Niu ${ }^{1}$ \\ ${ }^{1}$ School of Energy Science and Engineering, Henan Polytechnic University, Jiaozuo 454000, China \\ ${ }^{2}$ Henan Key Laboratory for Green and Efficient Mining \& Comprehensive Utilization of Mineral Resources, Jiaozuo 454000, \\ China \\ ${ }^{3}$ Collaborative Innovation Center of Coal Work Safety, Henan Province, Jiaozuo 454000, China
}

Correspondence should be addressed to Xiaojun Li; lxj@hpu.edu.cn

Received 22 June 2021; Accepted 24 November 2021; Published 15 December 2021

Academic Editor: Roger Serra

Copyright (C) 2021 Shuang Gong et al. This is an open access article distributed under the Creative Commons Attribution License, which permits unrestricted use, distribution, and reproduction in any medium, provided the original work is properly cited.

\begin{abstract}
Coal pillars left in coal mines are often subjected to long-term submersion by groundwater and chemical solutions and are susceptible to deterioration and even destabilization damage under dynamic load disturbance. In order to investigate the effects of acidic environment on dynamic mechanical properties and porosity evolution characteristics of coal, a split Hopkinson bar (SHPB) was used to test the dynamic compressive strength and tensile strength of coal samples under different acid environment. The results showed that the sample density gradually decreased with the increase of the number of wet and dry cycles, but the decrease was significantly related to the $\mathrm{pH}$ value. Longitudinal wave velocity of coal sample decreases gradually with the increase of drying and wetting cycles, and the decreasing speed is first fast and then slow. The stronger the acidity of the solution, the more times the dry-wet cycle, and the higher the water absorption of the sample. In the early stage of dry-wet cycle, the coal is significantly affected, and the average deterioration degree is large. After that, the influence of cyclic action is reduced, and the average degradation degree is small. Porosity of coal increases continuously under the action of dry-wet cycle. The stronger the acidity, the greater the change in initial porosity. In the 20th cycle, the porosity of the acidic environment increases significantly at once and then decreases continuously.
\end{abstract}

\section{Introduction}

The western mining areas of China are arid and semiarid ecologically fragile areas, where the precipitation is more than four times the evaporation. Its land area is 3.272 million square kilometers, accounting for $34 \%$ of the national land area, but the total water resources are less than $7 \%$ of the national total, with typical coal-rich and water-scarce characteristics. Coal mining in China is mainly shaft mining, and the coal seam is usually located under the aquifer, so the process of coal mining will produce a large amount of outgoing mine water [1]. Coal production requires large amounts of water resources, while mining activities often destroy the overlying rock aquifers resulting in water loss, accelerating the degradation of surface water-loving plants and desertification, weakening the ability of the surface to contain water, unable to provide enough water resources, and forming a vicious circle. Water resources have serious constraints on coal production, people's life, and ecological environment in western mining areas, and corresponding water conservation measures are urgently needed to alleviate this situation [2-4]. In response to this situation, some scholars have proposed the technical idea of using the mined-out area to construct an underground reservoir to store water resources $[3,5,6]$.

At present, China's underground water reservoir technology has been applied on-site in several coal mines, including Daliuta Coal Mine, Tsakhasu Coal Mine, and Ulanmulun Coal Mine. Topographical conditions and artificial measures are used to sink mine water into the mining area for storage and initial purification, providing water for production, living and ecological supply, and alleviating the 
problem of water supply tension in ecologically fragile mining areas in the west. The coal pillar dam body is an important part of the underground reservoir and is necessary for the safe operation of the underground reservoir. The repeated rise and fall of the water level in the underground reservoir during water injection and discharge causes repeated erosion of the coal pillar dam body, which has an important impact on the mechanical properties of the coal pillar dam body in the long run. There are relatively few studies related to the mechanical damage of coal pillar dams under repeated immersion in underground reservoirs, and similar repeated immersion studies are relatively more frequent in surface reservoir bank slopes. At the same time, the mine water in different regions has different acidity, which chemically interacts with the mineral composition within the coal pillar dam body and changes the loadbearing capacity of the coal pillar dam body [7, 8]. Most of the acidic mine water in China is distributed in the southwest. Coal mining oxidizes the associated sulfur iron ore into sulfuric acid through complex chemical reactions and microbial action, making the mine water acidic and more likely to dissolve heavy metal ions and other harmful elements.

As a discontinuous, nonhomogeneous, multiphase complex geological material, the mineral composition of the coal mass, and the presence of many internal irregular primary pores, fissures and other defects have a nonnegligible impact on the physical, mechanical, and chemical properties of the coal rock mass. The water-rock physical action is manifested as the lubrication, softening, and scouring between mineral particles, cement, and structural surfaces caused by water, which decreases the mechanical parameters of the material of saturated coal rock mass [9-14]. Especially when the coal rock mass contains many fine clay mineral particles, the particles have high water absorption. Percolation leads to particle softening and thickening of adsorbed water film triggering uneven volume expansion, and physical and mechanical characteristics are significantly affected by water. Referring to the boiling method, Yao et al. developed a more concise nondestructive water immersion device that uses water mist to create a saturated humidity environment to saturate the specimen [8]. Cui et al. [15] found that coal sedimentary rocks are prone to water sensitivity through laboratory experimental studies, and coal dust is more likely to swell in low mineralization fluids, promoting fracture space filling and reducing permeability, and is irreversible. Ding et al. [16] found that the loading path changed the manner of energy accelerate-release, there was more plastic strain generation in coal under cyclic loading than that under grade loading, the former was more likely to cause greater damage and failure, then the strength of coal under cyclic loading is generally lower than that under grade loading, and an energy conversion mechanical model of stress, damage, and deformation was developed and the effect of the loading path was explained. Wang et al. [17] reveal that the fracturing of the surrounding rock during underwater blasting is due to the combined action of shock and stress waves for the initial rock breakage and subsequent water expansion. The fracture development model for the surrounding rock of a drilling hole during underwater blasting is established. A quantitative study was performed on the degree of clustering, and space-time distribution curves are obtained. Under the threshold of $100 \mathrm{~km}, 47 \%$ of disasters are involved in cluster series and 372 coal mine disasters are accompanied by earthquakes. The majority of cluster series lasting for 1-2 days correspond well to earthquakes nearby, which are speculated to be related to local stress disturbance [18]. Huang et al. [19] found that Poisson's ratio was less than 0.5 by water immersion test of muddy dolomite, and the higher the water content, the larger the Poisson' ratio, and Poisson's ratio failed when rupture occurred inside the test. Xue et al. found that the bulk modulus and internal friction angle have a more sensitive influence on the stress drop than do the shear modulus and cohesion [20]. Jia et al. [21] studied the indoor water absorption and dewatering tests on muddy siltstone and found that the size reduction rate was the fastest when the saturation was reduced from 55\% to $40 \%$ during natural dewatering. Dou et al. collected prefractured sandstone specimens with different dip angles from the roof of a coal mine and performed uniaxial compression tests. The effect of prefractured inclination angle on its fracture mechanism was investigated by acoustic emission (AE) and scanning electron microscopy (SEM) [22].

Current research on acid mine water focuses on its ecological hazards and prevention measures, i.e., the dissolution and adsorption of various ions and elements accompanying the flow of acid mine water, and less on its effects on the mechanical properties and characterized structures of coal rocks. During the long-term operation of underground reservoirs in coal mining areas, the coal pillar dams are in long-term contact with water, and their stability is affected by both water-physical and water-chemical effects. Therefore, it is of reference significance for the design and maintenance of coal pillar dams in underground reservoirs to study the strength weakening and deformation damage characteristics of coal samples under repeated water immersion and acidic solution water chemistry.

Aiming at the complexity of the degradation mechanism of coal under the action of dry and wet cycles in acidic environment, the degradation laws of strength parameters and porosity properties of coal under the action of acidic environment $(\mathrm{pH}=2,4,7)$ and dry and wet cycles $(n=5,10$, $15,20,25)$ were investigated on the basis of microscopic tests, dynamic compression, and tensile tests of coal. The degradation mechanism of coal was explained using chemical kinetic theory and porosity evolution laws.

\section{Test Preparation}

2.1. Specimen Preparation. The coal samples were taken from No. 12 coal seam of Zhao Gezhuang mine. In order to study the dynamic compressive and tensile strength of the coal samples, cylindrical specimens and Brazilian disc specimens were prepared, respectively. To simulate the actual conditions of natural aqueous solutions, the lower limit of $\mathrm{pH}$ under acidic conditions was 2 with reference to Zhang et al. [23], and three types of water retention solutions were 
used: distilled water with $\mathrm{pH}=7$, acidic solution with $\mathrm{pH}=4$, and acidic solution with $\mathrm{pH}=2$. The mineral composition of the coal samples was determined, and then the coal samples were immersed in different $\mathrm{pH}$ values $(\mathrm{pH}=7,4$, and 2$)$ for $5,10,15,20$, and 25 dry and wet cycles. After the cycles, dynamic compression and tensile tests were performed on saturated samples and dry samples dried for 24 hours. Finally, the variation pattern of porosity was analyzed.

2.2. Experimental System. The loading device for dynamic mechanical testing of coal is a split Hopkinson pressure bar (SHPB) loading system. The SHPB rock dynamic mechanical testing system is shown in Figure 1. The Hopkinson rod is made of $35 \mathrm{CrMn}$ steel with a density of $7800 \mathrm{~kg} / \mathrm{m}^{3}$, a modulus of elasticity of $200 \mathrm{GPa}$, and a Poisson's ratio of 0.28 . The length and diameter of the input and output rods of the SHPB loading system are $2 \mathrm{~m}$ and $0.05 \mathrm{~m}$, respectively. A strain gauge is installed in the middle of the input and output rods to record the rod deformation. The start-up pressure of the SHPB loading device is set to $0.50 \mathrm{MPa}$. Figure 2 shows the dynamic balance verification of a typical coal sample. The results show that the specimen meets the force balance requirements during loading and can be analyzed by static theory.

\section{Results and Discussion}

3.1. Influence of Acid Environment on Quasistatic Mechanical Properties of Coal. The microstructure of coal sample is analyzed by X-ray diffraction, and the results are shown in Figure 3 and Table 1. After reaching the set number of drying and wetting cycles, the mass and size of the sample are measured, and then the density of the sample after drying and wetting cycles is obtained. It can be seen from Figure 4 that, with the increase of the number of dry-wet cycles, the density of the sample decreases gradually, but the decreasing range has a significant relationship with the $\mathrm{PH}$ value. The damage of the sample by dry and wet cycle is accumulated gradually. The stronger the acid of the solution, the greater the decrease of the density of the sample. Under the dry and wet circulation of acid solution, the soluble cement in the sample will be dissolved, and the mineral particles react with $\mathrm{H}+$ in the solution. Some mineral ions after the reaction will be separated along the channels of crack and hole, which will cause the quality of the sample to decline, but the appearance size of the sample after dry and wet cycle is not changed. Therefore, the density of the sample decreases. The stronger the acid of the solution, the more the dry and wet cycles, the larger the dissolution ratio of soluble cement, the higher the degree of mineral particles participating in the reaction, and the greater the density drop.

In the experiment, the longitudinal wave velocity of rock samples after different cycles was measured by intelligent acoustic instrument. It can be seen from Figure 5 that the longitudinal wave velocity of coal sample decreases gradually with the increase of drying and wetting cycles, and the decreasing speed is first fast and then slow. Under the combined action of complex dry-wet cycle and water- chemical reaction, the pore structure of the rock has changed to a certain extent, which is an important reason for the change of longitudinal wave velocity of coal samples. With the increase of drying and wetting cycles, the microcracks and microholes in the sample continue to sprout and develop, resulting in the gradual decrease of longitudinal wave velocity. The increase of solution acidity is helpful to the expansion and penetration of cracks and holes. Therefore, the stronger the solution acidity is, the greater the decrease of longitudinal wave velocity is.

Water absorption is an important index to measure the mechanical properties of rock. The size of water absorption is mainly determined by the number and size of pores, the arrangement of mineral particles, the strength of cementation between mineral particles, and the external force environment of rock. The smaller the water absorption rate is, the better the compactness of rock is, and the better its engineering properties are. The engineering test data show that the water absorption of hard igneous rock is generally less than $1 \%$, that of hard and dense sedimentary rock is about $3 \%$, and that of some loose and hydrophilic sedimentary rocks is generally more than $8 \%$ [19].

The water absorption can be calculated by the change of mass after the number of cycles, and the calculation formula is as follows:

$$
W=\frac{m_{2}-m_{1}}{m_{1}} \times 100 \%,
$$

where $W$ is the water absorption, $m_{1}$ is the average mass of the sample before erosion, and $m_{2}$ is the mass of the sample after wetting and drying cycle.

It can be seen from Figure 6 that, with the increase of the number of dry-wet cycles, the water absorption of the sample shows a gradual increasing trend, and the increasing speed is first fast and then slow. Under the action of acid dry-wet cycle, the pores and cracks in the sample develop continuously, which provides more channels for the penetration of the solution. The stronger the acidity of the solution, the more times the dry-wet cycle, and the higher the water absorption of the sample. Conversely, the increase in water absorption increases the opportunity for cement and mineral particles to come into contact with the solution. Therefore, there is a close relationship between the water absorption and the degree of damage.

The stress-strain curves of coal under uniaxial compression under different combination conditions are listed in Figure 7. It can be seen from the figure that the shape of the curve before the peak value is basically the same, which can be roughly divided into three stages: initial compaction stage, elastic deformation stage, and failure stage. When the specimen reaches the peak strength, it gradually fails and the curve decreases, and the specimen soon loses its bearing capacity, showing a certain plastic failure characteristic.

3.2. Effect of Acid Environment on Dynamic Mechanical Properties of Coal. In order to analyze the influence of acid environment on the dynamic strength of coal, the dynamic compression and tensile tests of coal were carried out to test 


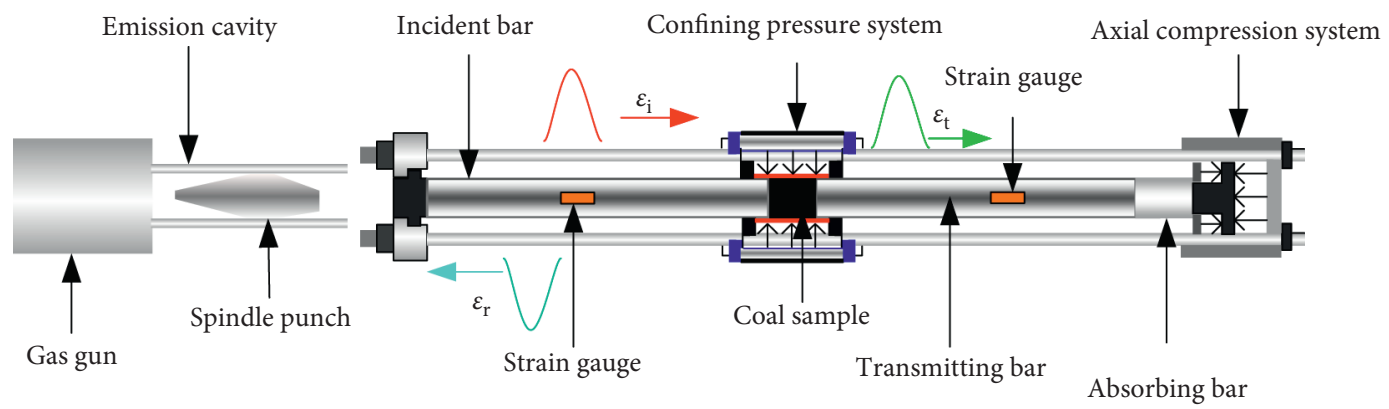

FIGURE 1: Structure and schematic diagram of the improved SHPB experimental device.

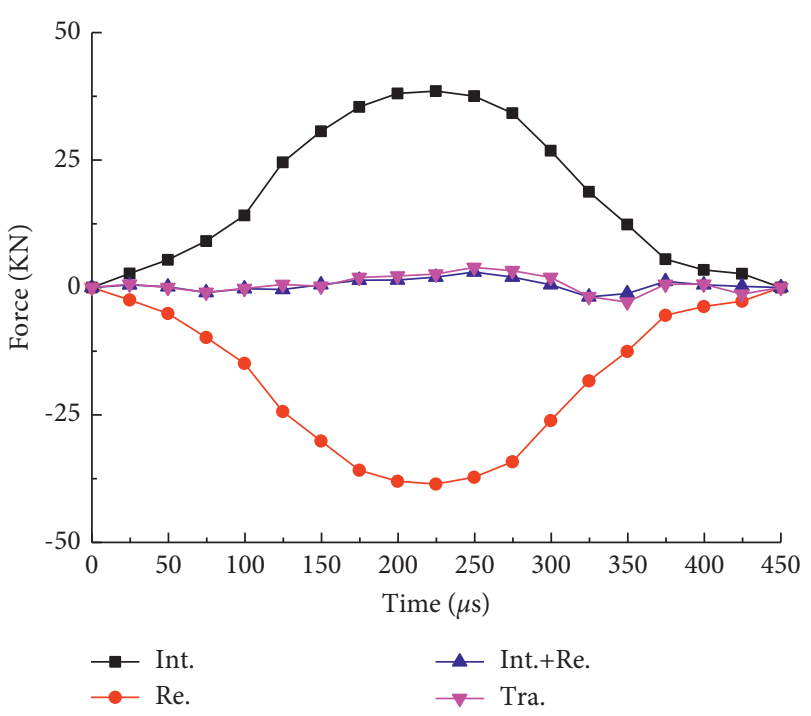

FIgURE 2: Dynamic force equilibrium.

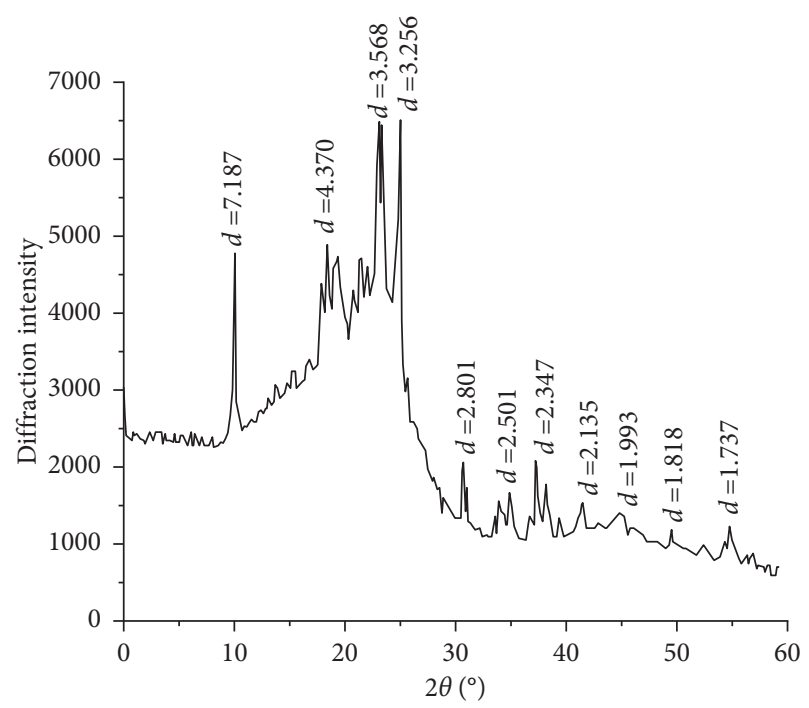

Figure 3: X-ray diffraction patterns of coal sample.

the influence of different $\mathrm{pH}$ values on the strength. The relationship between impact velocity and strain rate of dynamic impact is shown in Figure 8. It can be seen that the strain rate increases exponentially with the increase of impact velocity. The uniaxial stress-strain curves of coal under different acid environments were obtained by dynamic uniaxial compression test, as shown in Figure 9. The stress-strain curve can be divided into three stages, the first stage is elastic stage, the second stage is yield deformation stage, and the third stage is fracture stage.

The total degradation degree calculation formula is defined as

$$
D_{j}=\frac{\sigma_{c 0}-\sigma_{c j}}{\sigma_{c 0} \times 100 \%}
$$

where $\sigma_{c 0}$ is the uniaxial compressive strength of coal without soaking solution, and $\sigma_{c j}$ is the uniaxial compressive strength of the coal soaked for $j$ cycle stage.

Phase average deterioration is defined as

$$
D_{n}=\frac{D_{j}-D_{j-1}}{\left(n_{j}-n_{j-1}\right)},
$$

where $D_{j}$ is the total deterioration degree of coal after the $j$ cycle stage, and $n_{j}$ is the number of cycles.

The dynamic uniaxial compressive strength and deterioration degree of coal under different acid environments $(\mathrm{pH}=7,4,2)$ and different cycles $(n=5,10,15,20,25)$ are shown in Table 2. It can be seen from Figure 10 that the total deterioration degree $D_{j}$ increases gradually, which indicates that the damage of coal caused by dry-wet cycle is gradual. In the early stage of dry-wet cycle, the coal is significantly affected, and the average deterioration degree is large. After that, the influence of cyclic action is reduced, and the average degradation degree is small. The stronger the acidity is, the more the dynamic strength of coal decreases, and the total deterioration degree is the largest.

A total of 80 Brazilian splitting test specimens were divided into 16 groups, with a total of 5 specimens in each group. It can be seen from Table 3 and Figure 11 that the tensile strength of coal decreases with the increase of dry-wet cycles. The deterioration degree is faster in the early stage and slower in the late stage. Under acidic environment, the decrease amplitude of tensile strength of coal is obviously larger than that in neutral solution, which indicates that, under the action of acid solution soaking, the easily soluble minerals in coal react with hydrogen ions and hydroxyl ions in solution obviously, resulting in pores and microcracks, leading to the rapid formation of cracks in coal and full penetration. 
TABLE 1: XRD microcrystalline parameters of coal samples.

\begin{tabular}{lccccc}
\hline Types of coal samples & $2 \theta_{002}\left({ }^{\circ}\right)$ & $\beta_{002}(\mathrm{rad})$ & $2 \theta_{100}\left(^{\circ}\right)$ & $\beta_{100}(\mathrm{rad})$ & $L_{\mathrm{c}}(\mathrm{nm})$ \\
\hline Strong bursting liability & 24.1 & 0.176 & 42.9 & 0.312 & 0.868 \\
\hline
\end{tabular}

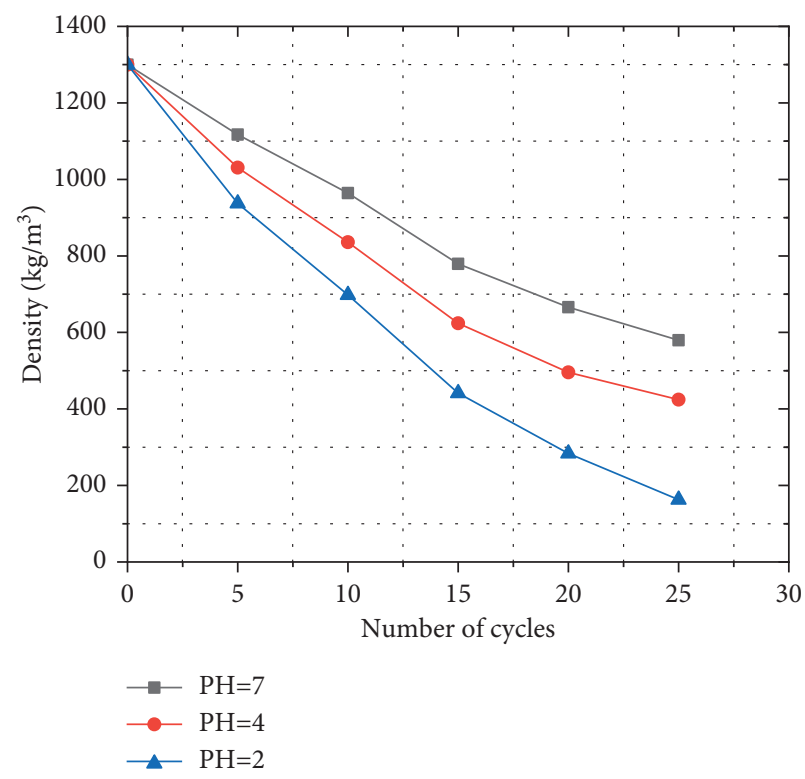

FIGURE 4: Variation of density of coal samples with cycle times in different acidic environments.

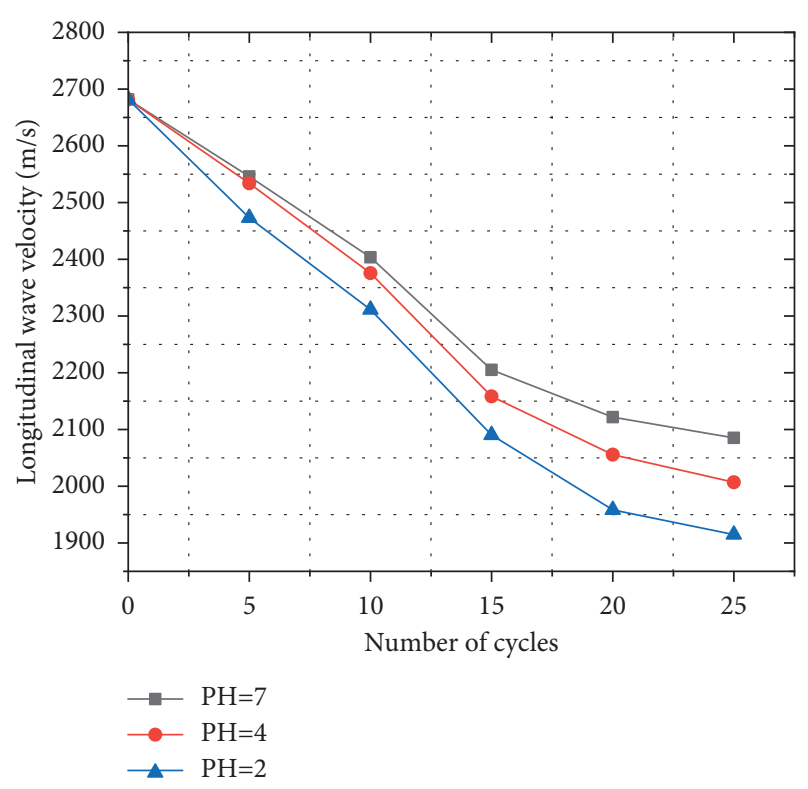

FIGURE 5: Variation of longitudinal wave velocity of coal samples with cycle times in different acidic environments.

\subsection{Influence of Acid Environment on Porosity Evolution of} Coal. The mechanism of damage of coal rocks under stress and physical and chemical action is not clear due to the complex structural surface and diverse mineral composition. Little research has been done under the influence of

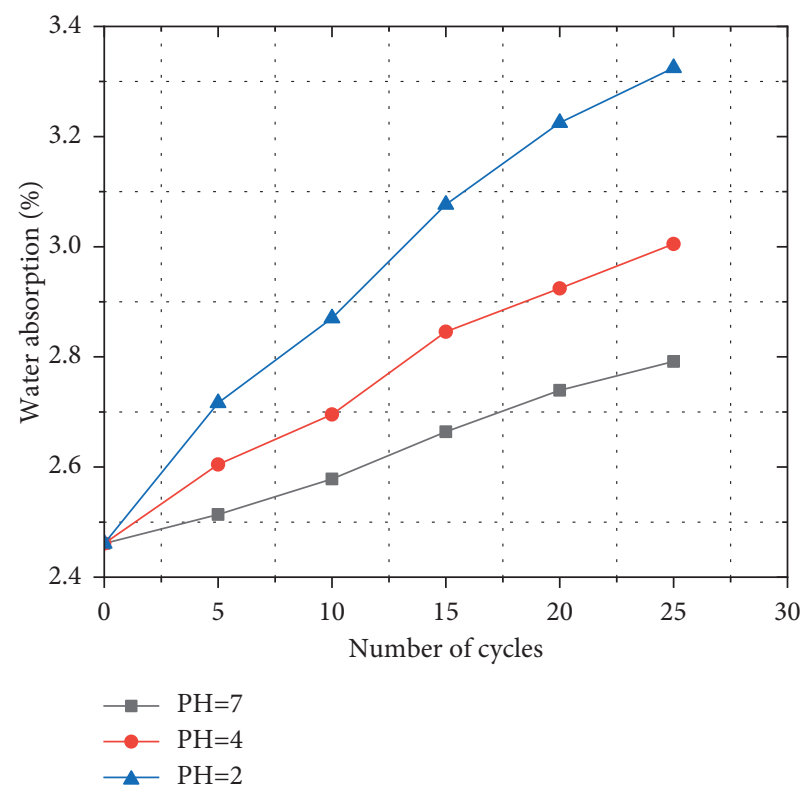

FIGURE 6: Variation of water absorption of coal samples with cycle times in different acidic environments.

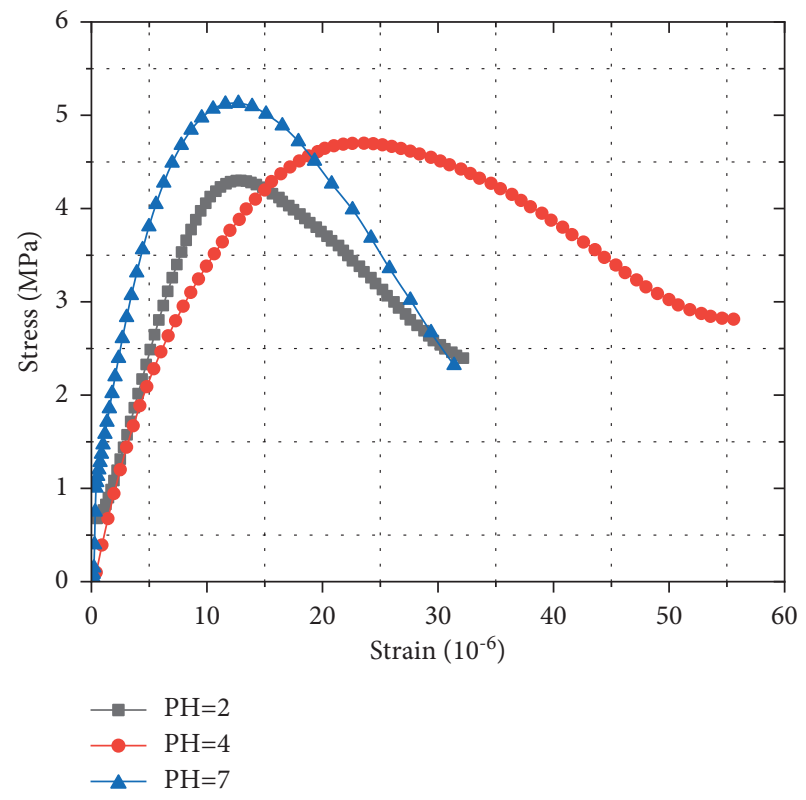

FIgURE 7: Stress-strain curves of coal under quasistatic conditions in different acid environments.

combined water-rock action and dynamic disturbance. However, the internal microstructure of coal rocks changes under the action of water-chemical solutions, which deteriorates their physical and mechanical properties and threatens the long-term stability of coal pillar dams or coal 


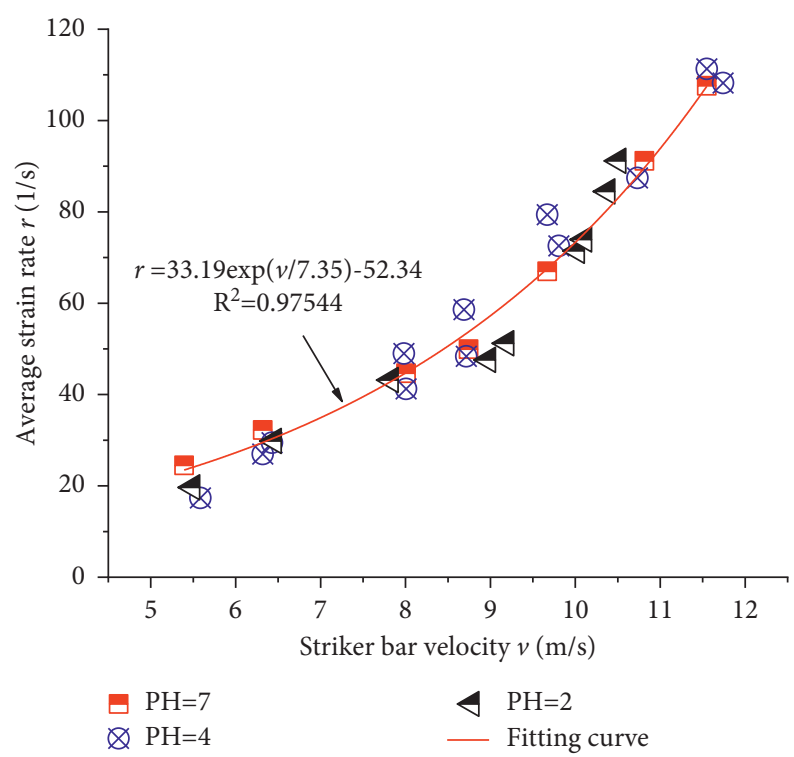

FIGURE 8: Relationship between average strain rate and striker bar velocity.

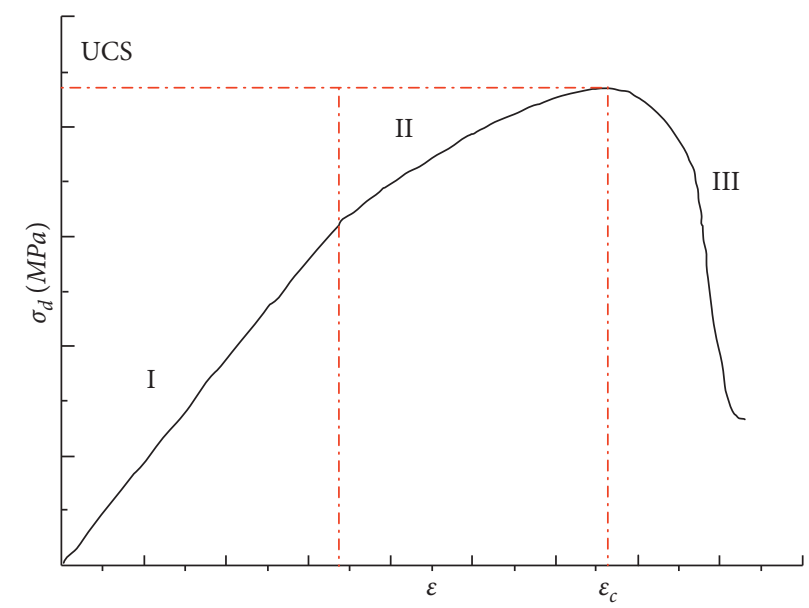

Figure 9: Typical dynamic stress-strain curves of coal sample.

TABLE 2: Dynamic uniaxial compressive strength and its deterioration of coal samples.

\begin{tabular}{|c|c|c|c|c|c|}
\hline $\mathrm{pH}$ & Number of cycles & Peak strength $(\mathrm{MPa})$ & Cycle phase & Total deterioration (\%) & Average deterioration of each stage (\%) \\
\hline \multirow{6}{*}{7} & 0 & 26.546 & 0 & 0.000 & 0.000 \\
\hline & 5 & 23.341 & 1 & 12.076 & 2.415 \\
\hline & 10 & 22.089 & 2 & 16.789 & 0.943 \\
\hline & 15 & 21.624 & 3 & 18.542 & 0.351 \\
\hline & 20 & 20.508 & 4 & 22.745 & 0.840 \\
\hline & 25 & 18.597 & 5 & 29.945 & 1.440 \\
\hline \multirow{5}{*}{4} & 5 & 22.756 & 1 & 14.279 & 10.512 \\
\hline & 10 & 20.961 & 2 & 21.041 & 1.353 \\
\hline & 15 & 19.607 & 3 & 26.139 & 1.020 \\
\hline & 20 & 18.543 & 4 & 30.148 & 0.802 \\
\hline & 25 & 17.583 & 5 & 33.765 & 0.723 \\
\hline \multirow{5}{*}{2} & 5 & 21.620 & 1 & 18.557 & 14.790 \\
\hline & 10 & 19.774 & 2 & 25.511 & 1.391 \\
\hline & 15 & 18.196 & 3 & 31.454 & 1.189 \\
\hline & 20 & 16.547 & 4 & 37.666 & 1.242 \\
\hline & 25 & 15.367 & 5 & 42.112 & 0.889 \\
\hline
\end{tabular}




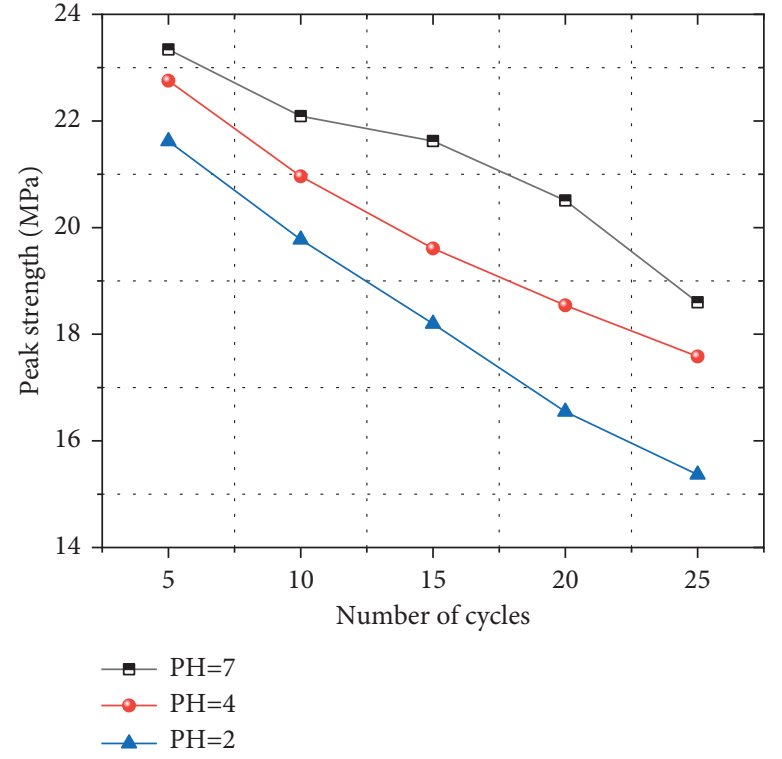

(a)

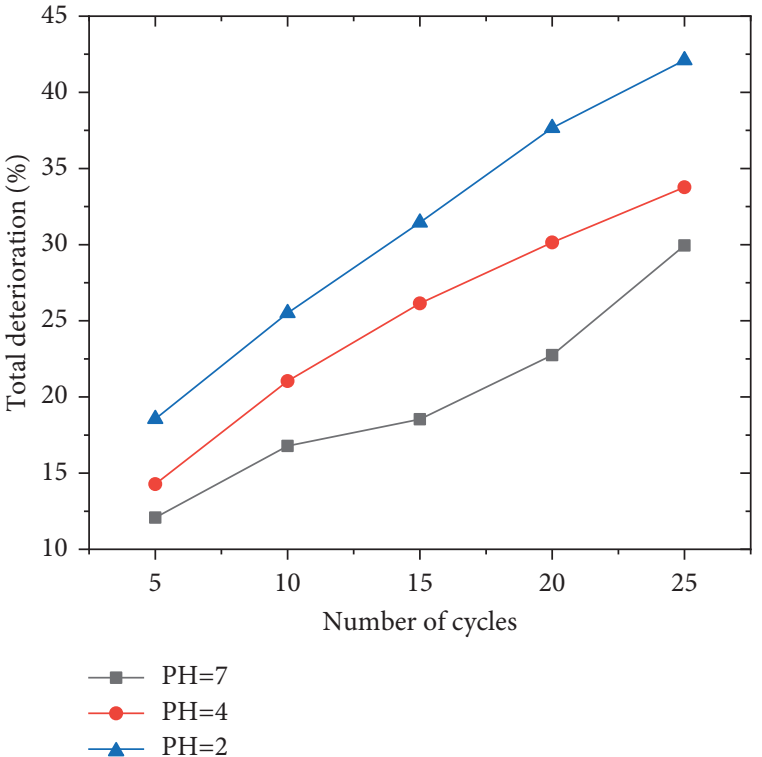

(b)

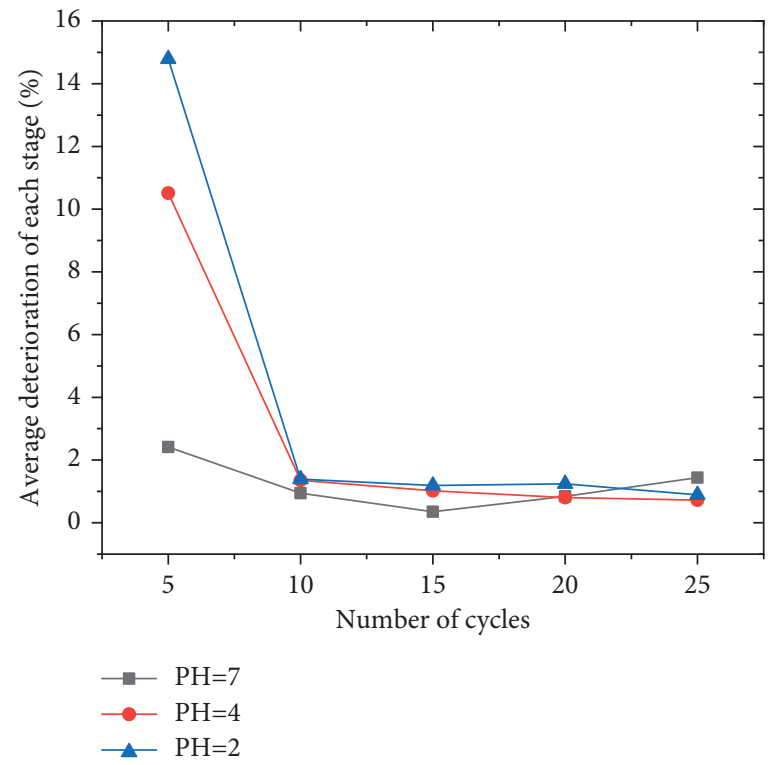

(c)

Figure 10: Comparison of deterioration degree of coal under uniaxial compression in different acid environments.

pillars left underground in coal mines. The variation of porosity has an important effect on the strength of coal rocks. The minerals of coal in chemical solutions undergo a complex series of physicochemical interactions with reactive particles in the solution (e.g., $\mathrm{H}+$ ). It leads to dissolution of the coal, which changes the pore structure and porosity of the coal. As a result of physicochemical processes such as reaction migration after water erosion, some active minerals in coal undergo dissolution, adsorption, and other processes. The dissolution reaction dissolves the minerals and the resulting ionic material migrates out of the coal to form pores. Adsorption causes many particles to cover the mineral surface of the coal, blocking the pore channels in the coal. The result of this reaction-migration-adsorption manifests itself as a change in the pore structure in the coal.

The change of porosity of coal samples during the action of aqueous solution is mainly caused by the dissolution and migration of component minerals in coal; therefore, the change of porosity of coal samples can be calculated by the following equation:

$$
\triangle \varphi=\varphi-\varphi_{0}=\sum_{i=1} \varphi_{i},
$$

where $\varphi$ is porosity, $\varphi_{0}$ is initial porosity, and $i$ refers to various minerals.

Incremental porosity of coal in each stage can be calculated by formula (4), as shown in Figure 12. The porosity 
Table 3: Dynamic tensile strength and its deterioration of coal samples.

\begin{tabular}{cccccc}
\hline $\mathrm{pH}$ & Number of cycles & Peak strength $(\mathrm{MPa})$ & Cycle phase & Total deterioration (\%) & Average deterioration of each stage (\%) \\
\hline & 0 & 2.910 & 0 & 0.000 & 0.000 \\
7 & 5 & 2.543 & 1 & 12.612 & 2.522 \\
& 10 & 2.420 & 2 & 16.838 & 0.845 \\
& 15 & 2.387 & 3 & 17.984 & 0.229 \\
& 20 & 2.257 & 4 & 22.451 & 0.893 \\
& 25 & 2.163 & 5 & 25.670 & 0.644 \\
4 & 5 & 2.450 & 1 & 15.808 & 10.512 \\
& 10 & 2.290 & 2 & 21.306 & 1.100 \\
& 15 & 2.173 & 3 & 25.315 & 0.802 \\
& 20 & 2.068 & 4 & 28.935 & 0.724 \\
& 25 & 1.982 & 5 & 31.890 & 0.591 \\
& 5 & 2.384 & 1 & 18.076 & 14.790 \\
& 10 & 2.264 & 2 & 22.199 & 0.825 \\
& 25 & 2.182 & 3 & 25.017 & 0.564 \\
\end{tabular}

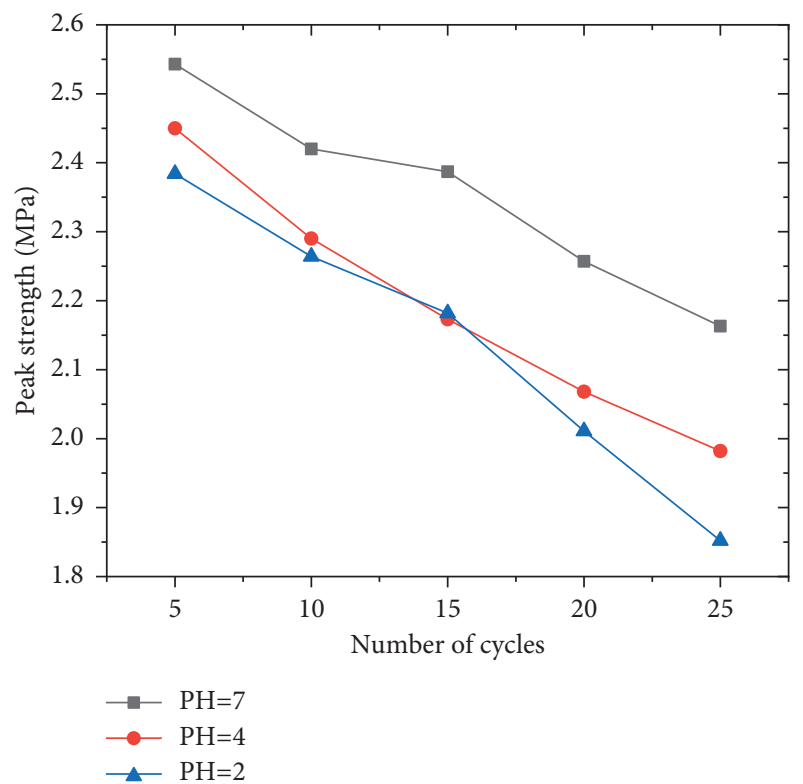

(a)

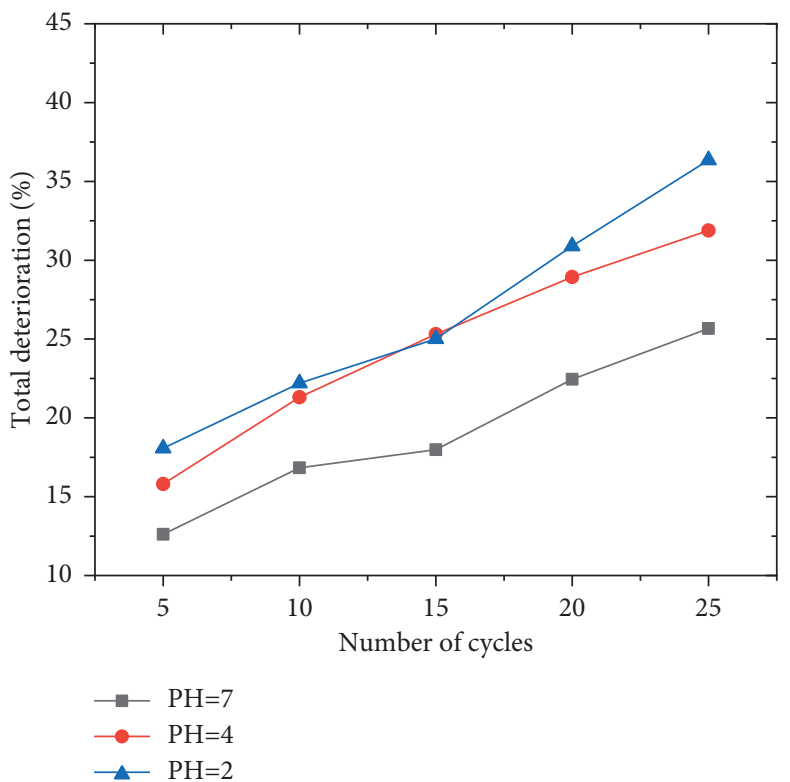

(b)

Figure 11: Continued. 


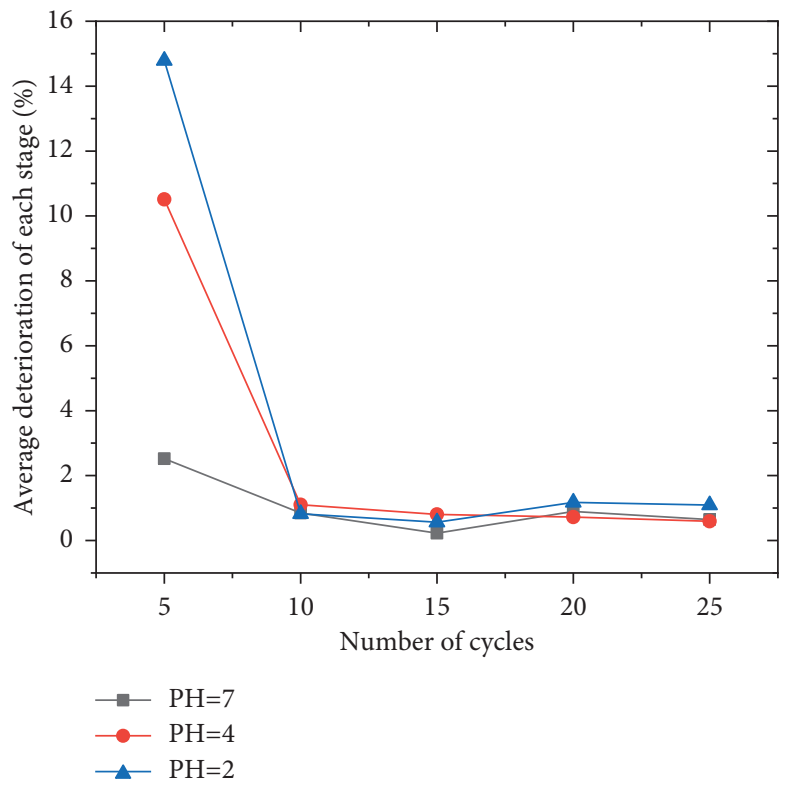

(c)

Figure 11: Comparison of deterioration degree of coal under uniaxial compression in different acid environments.

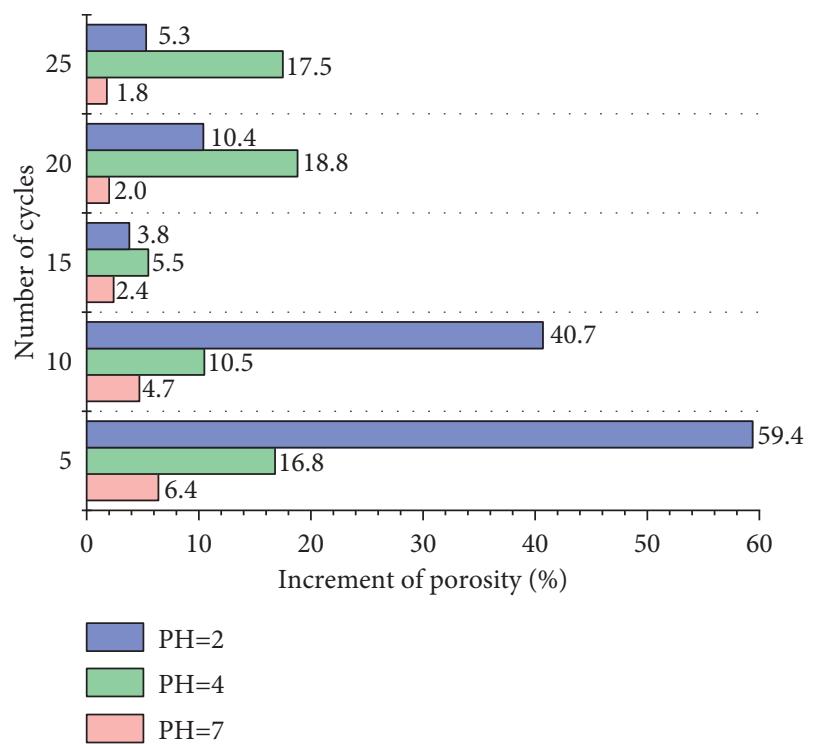

FIGURE 12: Increment change of coal porosity in different acid environment.

of coal increases continuously under the action of dry-wet cycle. Moreover, the stronger the acidity, the greater the change of initial porosity. At the 20th cycle, the porosity of acid environment increases significantly at one time and then decreases continuously.

\section{Conclusions}

(a) With the increase of the number of dry-wet cycles, the density of the sample decreases gradually, but the decreasing range has a significant relationship with the PH value. Longitudinal wave velocity of coal sample decreases gradually with the increase of drying and wetting cycles, and the decreasing speed is first fast and then slow.

(b) Under the action of acid dry-wet cycle, the pores and cracks in the sample develop continuously, which provides more channels for the penetration of the solution. The stronger the acidity of the solution, the more times the dry-wet cycle, and the higher the water absorption of the sample.

(c) The total deterioration degree $D_{j}$ increases gradually, which indicates that the damage of coal caused by dry-wet cycle is gradual. In the early stage of dry-wet cycle, the coal is significantly affected, and the average deterioration degree is large. After that, the influence of cyclic action is reduced, and the average degradation degree is small. The stronger the acidity is, the more the dynamic strength of coal decreases, and the total deterioration degree is the largest.

(d) Porosity of coal increases continuously under the action of dry-wet cycle. Moreover, the stronger the acidity, the greater the change of initial porosity. At the 20th cycle, the porosity of acid environment increases significantly at one time and then decreases continuously.

\section{Data Availability}

The data used to support the findings of this study are available from the corresponding author upon request.

\section{Conflicts of Interest}

The authors declare that there are no conflicts of interest regarding the publication of this paper. 


\section{Acknowledgments}

This work was financially supported by the Fundamental Research Funds for the Universities of Henan Province (Grant no. NSFRF200332), China Postdoctoral Science Foundation (no. 2021M701100), Key Research and Development and Promotion of Special (Science and Technology) Project of Henan Province (no. 212102310379), the research fund of Henan Key Laboratory for Green and Efficient Mining and Comprehensive Utilization of Mineral Resources (Henan Polytechnic University) (no. KCF201804), the Key Scientific Research Project Fund of Colleges and Universities of Henan Province (no. 21A610005 and no. 20B440001), and the Doctoral Foundation of Henan Polytechnic University (no. B2019-22). All supports are greatly appreciated.

\section{References}

[1] Q. Yao, C. Tang, Z. Xia et al., "Mechanisms of failure in coal samples from underground water reservoir," Engineering Geology, vol. 267, no. 1, Article ID 105494, 2020.

[2] Y. Wang, X. Liu, L. Liang, and J. Xiong, "Experimental study on the damage of organic-rich shale during water-shale interaction," Journal of Natural Gas Science and Engineering, vol. 74, Article ID 103103, 2019.

[3] S. Gong, L. Zhou, Z. Wang, and W. Wang, "Effect of bedding structure on the energy dissipation characteristics of dynamic tensile fracture for water-saturated coal," Geofluids, vol. 2021, no. 8, 10 pages, Article ID 5592672, 2021.

[4] C. Cattaneo, M. Manera, and E. Scarpa, "Industrial coal demand in China: a provincial analysis," Resource and Energy Economics, vol. 33, no. 1, pp. 12-35, 2011.

[5] S. Gong, "Investigation of tensile and fracture mechanical properties of bituminous coal at different strain rates," Journal of Materials Research and Technology, vol. 15, pp. 834-845, 2021.

[6] C. Zhang, F. Wang, and Q. Bai, "Underground space utilization of coalmines in China: a review of underground water reservoir construction," Tunnelling and Underground Space Technology, vol. 107, Article ID 103657, 2021.

[7] F. Wang, N. Liang, and G. Li, "Damage and failure evolution mechanism for coal pillar dams affected by water immersion in underground reservoirs," Geofluids, vol. 2019, no. 1, 12 pages, Article ID 2985691, 2019.

[8] Q. Yao, C. Zheng, C. Tang, Q. Xu, Z. Chong, and X. Li, "Experimental investigation of the mechanical failure behavior of coal specimens with water intrusion," Frontiers of Earth Science, vol. 7, p. 348, 2020.

[9] L. E. Mayhew, E. T. Ellison, T. M. McCollom, T. P. Trainor, and A. S. Templeton, "Hydrogen generation from low-temperature water-rock reactions," Nature Geoscience, vol. 6, no. 6, pp. 478-484, 2013.

[10] C. Yang, Z. Dai, K. D. Romanak, S. D. Hovorka, and R. H. Treviño, "Inverse modeling of water-rock-CO2 batch experiments: potential impacts on groundwater resources at carbon sequestration sites," Environmental Science and Technology, vol. 48, no. 5, pp. 2798-2806, 2014.

[11] L. Belkhiri, L. Mouni, and A. Tiri, "Water-rock interaction and geochemistry of groundwater from the Ain Azel aquifer, Algeria," Environmental Geochemistry and Health, vol. 34, no. 1, pp. 1-13, 2012.
[12] Z. L. Shen, Y. X. Wang, and H. M. Guo, "Opportunities and challenges of water-rock interaction studies," Earth Science Journal of China University of Geosciences, vol. 37, no. 2, pp. 207-219, 2012.

[13] A. Hiorth and S. Evje, "A Mathematical model for dynamic wettability alteration controlled by water-rock chemistry," Networks and Heterogeneous Media, vol. 5, no. 2, pp. 217-256, 2010.

[14] B. Dold, N. Diaby, and J. E. Spangenberg, "Remediation of a marine shore tailings deposit and the importance of waterrock interaction on element cycling in the coastal aquifer," Environmental Science and Technology, vol. 45, no. 11, pp. 4876-4883, 2011.

[15] J. Cui, W. Wang, C. Zhang, P. Yu, Z. Hu, and J. Liu, "Research and prevention of coal water-sensitive mechanism," Journal of Petrochemical Universities, vol. 28, no. 2, pp. 54-57, 2015.

[16] X. Ding, X.-C. Xiao, D. Wu, and X.-F. Lv, "Mechanical properties and charge signal characteristics in coal material failure under different loading paths," International Journal of Coal Science \& Technology, vol. 6, no. 1, pp. 138-149, 2019.

[17] J. Wang, J. Yang, F. Wu, T. Hu, and S. A. Faisal, "Analysis of fracture mechanism for surrounding rock hole based on water-filled blasting," International Journal of Coal Science \& Technology, vol. 7, no. 4, pp. 704-713, 2020.

[18] B. Chen, "Stress-induced trend: the clustering feature of coal mine disasters and earthquakes in China," International Journal of Coal Science \& Technology, vol. 7, no. 4, pp. 676692, 2020.

[19] Y. Huang, J. Deng, S. Zhong, D. Sheng, and V. Zhu, "Experimental study on mechanical property of argillaceous dolomite with different moisture content," Chinese Journal of Underground Space and Engineering, vol. 10, no. 2, pp. 276284, 2014.

[20] D. Xue, J. Zhou, Y. Liu, and L. Gao, "On the excavationinduced stress drop in damaged coal considering a coupled yield and failure criterion," International Journal of Coal Science \& Technology, vol. 7, no. 1, pp. 58-67, 2020.

[21] H. Jia, T. Wang, W. Xiang, L. Tan, Y. Shen, and G. Yang, "Influence of water content on physical and mechanical properties of argillaceous siltstone," Journal of Rock Mechanics and Engineering, vol. 37, no. 7, pp. 1618-1628, 2018.

[22] L. Dou, K. Yang, and X. Chi, "Fracture behavior and acoustic emission characteristics of sandstone samples with inclined precracks," International Journal of Coal Science \& Technology, vol. 8, no. 1, pp. 77-87, 2021.

[23] Y. Zhang, J. Sun, and X. Chen, "Characteristics and preliminary analyses of the formation of $\mathrm{pH}$ in shallow groundwater in the Pearl River delta," Hydrogeology \& Engineering Geology, vol. 38, no. 1, pp. 16-21, 2011. 